\title{
NIVELES DE MALONDIALDEHIDO Y CATALASA EN TEJIDOS DE COBAYOS NATIVOS DE LA ALTURA
}

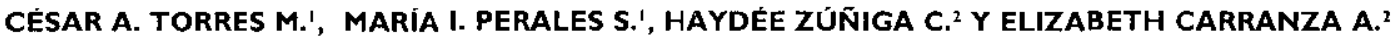 \\ 'DEPARTAMENTO ACADÉMICO DE BIOQUIMICA, FACULTAD DE FARMACIA Y BIOQUÍMICA, \\ 'INSTITUTO NACIONAL DE BIOLOGIA ANDINA, FACULTAD DE MEDICINA HUMANA, \\ UNIVERSIDAD NACIONAL MAYOR DE SAN MARCOS
}

\begin{abstract}
RESUMEN
Se evaluaron los niveles de malondialdehido (MDA) y la actividad de la catalasa en corazón, riñón, higado y pulmón de cobayos nacidos y criados en la altura (Cullhuay, $3642 \mathrm{~m}$ ), y un grupo similar a nivel del mar (La Molina, $238 \mathrm{~m}$ ), con el fin de establecer si existen diferencias en las concentraciones y la actividad mencionadas entre los dos grupos, y comprender mejor el proceso del estrés oxidativo de los habitantes de las grandes alturas. Se determinó MDA usando el método del nmetil-1-fenilindol, y la actividad de la enzima catalasa por el método colorimétrico del PURPALD. En los tejidos de corazón, riñón, hígado y pulmón de cobayos de altura se obtuvo: concentraciones de MDA en mmoles/g proteína de: 0.309, 0.158, 0.133 y 0.257 , valores significativamente mayores que a nivel del mar: $0.263,0.115,0.097$ y 0.201 ( $p<0.05)$; y actividad de catalasa expresada en mmoles de formaldehído producido/g proteína de: $0.693,0.268,0.552$ y 0.311 , valores significativamente menores que a nivel del mar: $0.784,0.319,0.628$ y 0.377 ( $p<0.05$ ). Estos hallazgos hacen evidente una asociación entre la hipoxia crónica y un incremento en la generación de radicales libres; así como que en la hipoxia crónica disminuye la acción protectora del sistema de defensa antioxidante, representado en este estudio por la enzima catalasa. No se encontraron correlaciones significativas entre catalasa y MDA.
\end{abstract}

Palabras Claves: Peroxidación lipidica; radicales libres; $M D A$, catalasa, hipoxia

\section{SUMMARY}

In the present study, levels of malondialdehyde (MDA), end product of lipid peroxydation, and activity of catalase, a protective enzyme, in heart, kidney, liver and lung of guinea pigs born and bred in the altitude (Cullhuay, $3642 \mathrm{~m}$ ), and another from sea level (La Molina, $238 \mathrm{~m}$ ), were determined, in order to establish whether there exist any differences, and better understand of the oxydative stress in high altitude natives. Tissue levels of MDA were assessed by the $n-m e t h y l-1-$ phenylindol method, and catalase enzyme activity was evaluated using the PURPALD colorimetric method. In tissue of heart , kidney, liver and lung of high altitude guinea pig were found MDA concentrations in mmoles/g protein: $0.309,0.158,0.133$ and 0.257 , values significantly higher in high altitude guinea pig than in those from sea level: $0.263,0.115,0.097 \mathrm{y} 0.201 \mathrm{p}$ $<0.05$ ); and the value of catalase activity, expressed in mmoles of formaldehyde produced/g protein: $0.693,0.268,0.552$ and 0.311 , significantly lower in those from sea level..784, 0.319, 0.628 and $0.377(\mathrm{p}<0.05)$. These findings make evident an association between chronic hypoxia and an increased gencration of frec radicals, and also that in chronic hypoxia diminishes the protective action of the antioxydative defense system, here represented by catalase enzyme. No significant correlations between catalase and MDA were found.

Key word: Lipid peroxydation; Free radicals, MDA, catalasc, hypoxia

\section{INTRODUCCIÓN}

Un radical libre es una molécula o fragmento molecular que contiene uno o más electrones despareados en el orbital mas externo $(1,2)$. Una molécula puede convertirse en radical libre tanto por ganancia como por pérdida de electrones y también por fisión de enlaces homolíticos. Al rom- perse un enlace covalente en forma simétrica, ambos fragmentos retienen un electrón, y por tanto, se convierten en radical libre. Este electrón desapareado le confiere al radical libre una cierta inestabilidad tanto energética como cinética, lo que los hace compuestos altamente reactivos. Constituyen ejemplos de radicales libres: el átomo de hidrógeno $(\mathrm{H})$, la molécula de triclorometilo $\left(\mathrm{CCl}_{3}\right)$, el anión 
superóxido $\left(\mathrm{O}_{2}^{-}\right)$, el radical hidroxilo $(\mathrm{OH})$, óxidos de nitrógeno como el óxido nítrico (NO), radicales peróxilo $\left(\mathrm{RO}_{2}\right)$, alcóxilo $(\mathrm{RO})$, entre otros $(1,2)$.

El estudio de los radicales libres se ha enfocado desde el punto de vista clínico y celular, ya que la interacción de estos compuestos con las moléculas orgánicas se ha relacionado con el daño tisular y la génesis de diversas patologías $(3,4,5,6,7,8,9,10)$.

Las células cuentan con mecanismos de protección enzimática (Superóxido dismutasa, Catalasa, Glutation peroxidasa, etc.) y no enzimáticos (Vitaminas $\mathrm{E}$ y C), además de otros removedores $(6,8,11,12,13,14,15)$. Un desbalance entre la producción de especies radicales libres y los sistemas de defensa antioxidante celular favorecerá la aparición del estrés oxidativo.

El daño celular, que resulta de una producción excesiva de radicales libres de oxígeno (estrés oxidativo), ha tratado de ser explicado como consecuencia de una alteración de la membrana celular a través de la oxidación de los residuos de ácidos grasos de la bicapa lipídica, proceso que se ha convenido en denominar peroxidación lipidica. Se considera que la peroxidación lipídica ocasiona cambios en la composición química, y deterioro en la organización ultraestructural de las membranas celulares, disminuyendo la fluidez de las mismas, alterando su permeabilidad e inactivando enzimas y receptores ligados a la membrana $(5,16,16,17,18)$.

Los lípidos peroxidados son inestables y se descomponen formando una compleja serie de compuestos que incluye los compuestos carbonil reactivos (aldehídos). La concentración de tales aldehidos se relaciona directamente con el nivel peroxidativo en las muestras biológicas $(5,8,17,19,20)$. Estos aldehídos pueden difundir desde el lado de su origen (Ej. membranas), alcanzar y atacar blancos situados intra y extracelularmente, los cuales están distantes del evento inicial asociado al radical libre $(5,8,17,19,20)$.

La peroxidación lipídica es un amplificador para los radicales libres iniciales, y los aldehídos reactivos generados en estos procesos pueden actuar como «segundos mensajeros tóxicos» en la compleja cadena de reacciones que se inician si los ácidos grasos polinnsaturados de la bicapa de la membrana son convertidos en lípidos hidroperóxidos $(5,8,17,19,20)$. Entre los diferentes aldehídos que pueden formarse en el proceso de peroxidación lipidica, y que más se han estudiado son: el malondialdehido y el 4-hidroxialquenal, en particular el 4-hidroxinonenal (HNE) y 4hidroxihexenal $(16,17,20)$.
Dada la relación directa entre la producción de estos aldehídos reactivos y la peroxidación lipídica, la evaluación de la concentración de uno de estos subproductos nos dará información del nivel del estrés oxidativo en la muestra estudiada. En otros términos estos aldehídos pueden considerarse como indicadores del estrés oxidativo $(17,20)$. Se puede medir el nivel de la peroxidación lipídica a través de la estimación cuantitativa y espectrofotométrica de algún subproducto de tal proceso, siendo el de preferencia, el malondialdehido $(7,26)$.

Las fuentes potenciales de producción de radicales libres que promueven la peroxidación de los ácidos grasos pueden ser las reacciones de autooxidación donde interviene el ión $\mathrm{Fe}^{2+}$. El hierro puede provenir de la hemoglobina o de la ferritina. El peróxido de hidrógeno formado normalmente puede liberar ión $\mathrm{Fe}^{2+}$ de la hernoglobina y así estimular la peroxidación de los lípidos de la membrana celular $(16,22)$.

El principal mecanismo de adaptación a la menor presión parcial de oxígeno de las grandes alturas es el incremento en el numero de hematies, niveles de hemoglobina y hematocrito (21).

Existen muy pocos estudios sobre el proceso oxidativo en la altura. El objetivo del presente estudio es evaluar los niveles de malondialdehido, y la activióad de la catalasa en diferentes tejidos de cobayos nativos de la altura y establecer si hay diferencias con los del nivel del mar, con la finalidad de incrementar los conocimientos del proceso del estrés oxidativo de los habitantes de las grandes alturas y comprender mejor el proceso biológico.

El trabajo se realizó en la localidad de Cullhuay del distrito de Huaros, provincia de Canta, ubicado a $3,632 \mathrm{~m}$.s.n.m., favorable para poder desarrollar la presente investigación y estar relativamente cerca de nuestra ciudad, y en La Molina (238 m.s.n.m.), Lima.

\section{MATERIAL Y METODOS}

Animales. Se utilizó cobayos machos y adultos de aproximadamente 16 semanas y de un peso promedio de $450 \mathrm{~g}$ repartidos en dos grupos experimentales: a) Grupo nativo de la altura: 10 cobayos nacidos y criados bajo las mismas condiciones en la localidad de Cullhuay $(3642 \mathrm{~m}$ ) de la provincia de Canta b) Grupo nativo del nivel del mar: 10 cobayos nacidos y criados bajo las mismas condiciones en la localidad de La Molina $(238 \mathrm{~m})$ de la ciudad de Lima. 
Extracción y tratamiento de la muestra Los cobayos fueron sacrificados por decapitación y desangrados; inmediatamente se extrajo los órganos: hígado, rinoón, pulmón y corazón, a los cuales se les eliminó la sangre usando solución salina isotónica.

Los cobayos de altura fueron sacrificados en la localidad de Cullhuay y las muestras fueron almacenadas a $-70^{\circ} \mathrm{C}$ haciendo uso de la mezcla refrigerante de $\mathrm{CO}_{2}-\mathrm{Metanol}$ hasta el momento del ensayo.

En cada uno de los órganos se determinó la concentración de Malondialdehido (MDA) y la actividad de la enzima catalasa:

a.Determinación de la concentración de malondialdehido. Se pesó el tejido y preparó un homogenizado al $30 \%(\mathrm{w} / \mathrm{v})$ en buffer Tris $20 \mathrm{mM}$, pH 7.4 conteniendo $5 \mathrm{mM}$ de Hidroxitolueno butilado (BHT). Para esta determinación se usó el método del N-metil-2-fenilindol, cuyo ensayo se basa en la reacción de un reactivo cromogénico (23), el N-metil-2-fenilindol, con el malondialdehido a $45^{\circ} \mathrm{C}$. Una mol de malondialdehido reacciona con dos moles del Nmetil-2-fenilindol para producir un cromóforo estable con una absorbancia máxima a $586 \mathrm{~nm}$. El procedimiento consiste en colocar en un tubo de ensayo: $400 \mathrm{ml}$ de muestra (sobrenadante del homogenizado), $1.3 \mathrm{ml}$ de la solución diluida de $\mathrm{N}$-metil-2-fenilindol (Preparado a la concentración de $10.3 \mathrm{mM}$ en acetonitrilo y diluido en la proporción de 3:1 con metanol, ambos grado HPLC). Mezclar en vortex. Adicionar $300 \mathrm{ml}$ de $\mathrm{HCl} 37 \%$. Mezclar por inversión, incubar a $45^{\circ} \mathrm{C}$ por $60 \mathrm{~min}$. Centrifugar las muestras opalescentes por $10 \mathrm{~min}$. El sobrenadante claro trasvasarlo a un tubo de lectura. Leer la absorbancia en el espectrofotómetro a $586 \mathrm{~nm}$. Se utilizó comó estándar: 1,1,3,3 tetrametoxipropano de Sigma, preparado a la concentración de $10 \mathrm{mM}$ en buffer tris- $\mathrm{HCl} 20 \mathrm{mM}, \mathrm{pH} 7.4$.

b.Determinación de la actividad de la Catalasa. Se pesó el tejido y preparó un homogenizado al $20 \%$ (w/v) en buffer $\mathrm{KH}_{2} \mathrm{PO}_{4}-\mathrm{NaOH} 25 \mathrm{mM}$, pH 7.0. Para esta determinación empleamos el método espectrofotométrico (24) que usa Purpald como cromógeno y que se basa en que la catalasa cataliza la descomposición del peróxido de hidrógeno $\left(\mathrm{H}_{2} \mathrm{O}_{2}\right)$ en dos pasos: En un primer momento se forma un intermediario entre la enzima y el $\mathrm{H}_{2} \mathrm{O}_{2}$, luego la actividad peroxidativa de la enzima cataliza la reacción del intermediario con un donador de hidrógenos como el metanol. Finalmente medimos espectrofotométricamente la producción de formaldehído (metanol oxidado) con el 4-amino-3-hidrazino-5-mercapto-1,2,4triazole (Purpald), el cual reacciona con el aldehído formando un compuesto heterocíclicobicíclico de color rosa pálido, el cual cambia a un tono púrpura intenso por una posterior reacción oxidativa.. Con el fin de evitar la interferencia de la sangre, el método fue modificado añadiendo una etapa de precipitación con hidróxido de bario $0.3 \mathrm{~N}$ y sulfato de zinc al $5 \%$, antes de añadir el Purpal. El procedimiento consiste en colocar en un tubo de centrífuga lo siguiente: $200 \mathrm{ml} \mathrm{de} \mathrm{bu-}$ ffer $\mathrm{KH}_{2} \mathrm{PO}_{4}-\mathrm{NaOH} 250 \mathrm{mM}, 200 \mathrm{ml}$ de metanol $24.34 \mathrm{M}, 25 \mathrm{ml}$ de $\mathrm{H}_{2} \mathrm{O}_{2} 0.47 \%, 400 \mathrm{ml}$ de muestra (sobrenadante del homogenizado centrifugado). Mezclar con vortex. Incubar a $20^{\circ} \mathrm{C}$ por exactamente $20 \mathrm{~min}$. Agregar $200 \mathrm{ml}$ de $\mathrm{KOH} 7.8 \mathrm{M}$, agregar $300 \mathrm{ml}$ de $\mathrm{Ba}(\mathrm{OH})_{2} 0.3 \mathrm{~N}$. Agitar con vortex. Reposo por $2 \mathrm{~min}$. Agregar $300 \mathrm{ml}$ de $\mathrm{ZnSO}_{4}$ al $5 \%$. Mezclar en vortex. Reposo por $10 \mathrm{~min}$. Centrifugar por $10 \mathrm{~min}$. Tomar $1,2 \mathrm{ml} \mathrm{del}$ sobrenadante y trasvasar a un tubo calibrado, añadir $400 \mathrm{ml}$ de Purpald ( $34.2 \mathrm{mM}$ en una solución $480 \mathrm{mM}$ de $\mathrm{HCl}$.). Incubar a $20^{\circ} \mathrm{C}$ por $10 \mathrm{~min}$. Adicionar $200 \mathrm{ml}$ de $\mathrm{KIO}_{4}(65.2 \mathrm{mM}$ en una solución $470 \mathrm{mM}$ de $\mathrm{KOH}$ ). Reposo por $10 \mathrm{~min}$. Leer Ia absorbancia a $550 \mathrm{~nm}$. El blanco de la muestra se preparó por adición de $400 \mathrm{ml}$ de $\mathrm{HCl} 480 \mathrm{mM}$, en lugar del reactivo cromogénico Purpald. El blanco de reactivos se preparó por adición de 400 $\mathrm{ml}$ de buffer $\mathrm{KH}_{2} \mathrm{PO}_{4}-\mathrm{NaOH} 25 \mathrm{mM}$, pH 7 en lugar de la muestra. La curva estándar se preparó por adición de $400 \mathrm{ml}$ de solución estándar de formaldehído en lugar de la muestra problema. Las concentraciones usadas fueron de: 12.32; $24.64 ; 36.96$ y $49.28 \mathrm{mM}$.

c. Determinación de Proteínas. Para la determinación de proteínas se usó el método de Folin-Lowry (25).

Análisis Estadístico. Los resultados se expresan en términos de medias y desviación estándar. Se aplica la prueba de Tukey para localizar las diferencias significativas entre las medias de MDA y actividad de catalasa correspondientes a los órganos estudiados. Y se efectúa el análisis de correlación. Todo resultado con valor asociado de $\mathrm{p}<0.05$ se considera significativo.

\section{RESULTADOS}

En la Tabla 1 se presentan los valores medios de MDA expresados en $\mu$ moles/ $g$ de proteína de los cuatro órganos de cobayos tanto del nivel del mar como de la altura.

Al comparar ambos grupos observamos que el nivel de MDA en los órganos de cobayos oriundos de la altura son significativamente mayores $(p<0.05$ en todos los casos). 
En la tabla 2 se presentan los valores medios de la actividad de la enzima catalasa expresados en $\mu$ moles de Formaldehido producido/g de proteí na. Como puede apreciarse, los valores son significativamente menores en los órganos de los cobayos de altura que en los de nivel del mar (corazón e hígado, $\mathrm{p}<0.01$; riñón y corazón, $\mathrm{p}<0.05$ ).

Al efectuar la comparación de medias por órgano, según la prueba de Tukey (Tabla 3), se obtiene para MDA al nivel del mar tres subconjuntos homogé neos: corazón (nivel alto), pulmón (nivel intermedio) y riñón e hígado (niveles bajos), donde las medias de riñón $y$ de hígado no difieren significativamente; mientras que en la altura resultan dos subconjuntos homogéneos: corazón y pul- món (niveles altos) y riñón e hígado (niveles bajos).

De la comparación de medias de catalasa por órgano, según la prueba de Tukey (Tabla 4), se obtiene tanto al nivel del mar como en la altura tres subconjuntos homogéneos: corazón, con nivel alto, significativamente diferente de los demás órganos; hígado, con nivel intermedio, también significativamente diferente de los demás órganos, y un grupo que reúne pulmón y riñón, con niveles bajos, que no difieren significativamente uno de otro, sî con respecto a los demás.

El coeficiente de correlación entre catalasa y MDA no es significativo, ni entre todos los datos de todos los órganos (correlación total), ni en cada órgano.

Tabla 1. Malondialdehido en Cobayos de nivel del mar y altura ( $\mu$ moles/ $g$ proteina)

\begin{tabular}{|l|c|c|c|c|}
\hline Órgano & $\mathrm{N}$ & $\begin{array}{c}\text { Nivel del Mar } \\
\text { Media } \pm \mathbf{D E}\end{array}$ & $\begin{array}{c}\text { Altura } \\
\text { Media } \pm \mathrm{DE}\end{array}$ & $\mathrm{p}$ \\
\hline Corazón & 10 & $0.263 \pm 0.030$ & $0.309 \pm 0.037$ & $<0.05$ \\
Riñón & 10 & $0.115 \pm 0.032$ & $0.158 \pm 0.037$ & $<0.05$ \\
Hígado & 10 & $0.097 \pm 0.014$ & $0.133 \pm 0.030$ & $<0.05$ \\
Pulmón & 10 & $0.201 \pm 0.044$ & $0.257 \pm 0.057$ & $<0.05$ \\
\hline
\end{tabular}

Tabla 2. Actividad de la Catalasa en Cobayos de nivel del mar y altura ( $\mu$ moles de formaldehído producido/g proteína)

\begin{tabular}{|l|c|c|c|c|}
\hline \multicolumn{1}{|c|}{ Órgano } & $\mathrm{N}$ & $\begin{array}{c}\text { Nivel del Mar } \\
\text { Media } \pm \mathrm{DE}\end{array}$ & $\begin{array}{c}\text { Altura } \\
\text { Media } \pm \mathrm{DE}\end{array}$ & $\mathrm{p}$ \\
\hline Corazón & 10 & $0.784 \pm 0.083$ & $0.693 \pm 0.075$ & $<0.01$ \\
Riñón & 10 & $0.319 \pm 0.052$ & $0.268 \pm 0.040$ & $<0.05$ \\
Higado & 10 & $0.628 \pm 0.061$ & $0.552 \pm 0.068$ & $<0.01$ \\
Pulmón & 10 & $0.377 \pm 0.060$ & $0.311 \pm 0.052$ & $<0.05$ \\
\hline
\end{tabular}

Tabla 3. Malondialdehido en Cobayos de nivel del mar y altura. Comparaciones Múltiples de Medias ( $\mu$ moles/g proteina). Subconjuntos Homogéneos de Tukey $(\mathrm{p}<0.05)$

\begin{tabular}{|c|c|c|c|c|}
\hline Lugar & Organo & \multicolumn{3}{|c|}{ Subconjuntos } \\
\hline \multirow{4}{*}{ Nivel del Mar } & CORAZÓN & 0.263 & & \\
& PULMÓN & & 0.201 & \\
& RINON & & & 0.115 \\
& HIGADO & & & 0.097 \\
\hline \multirow{4}{*}{ Altura } & CORAZÓN & 0.309 & & \\
& PULMÓN & 0.257 & & 0.158 \\
& RINÓN & & & 0.133 \\
\hline
\end{tabular}


Tabla 4. Catalasas en Cobayos de nivel del mar y altura. Comparaciones Múltiples de Medias ( $\mu$ moles/g proteína). Subconjuntos Homogéneos de Tukey $(\mathrm{p}<0.05)$

\begin{tabular}{|c|c|c|c|c|}
\hline Lugar & Organo & \multicolumn{3}{|c|}{ Subconjuntos } \\
\hline \multirow{3}{*}{ Nivel del Mar } & CORAZÓN & 0.784 & & \\
& PULMÓN & & 0.628 & \\
& RINÓN & & & 0.377 \\
& HIGADO & & & 0.319 \\
\hline \multirow{4}{*}{ Altura } & CORAZÓN & 0.693 & & \\
& PULMÓN & & 0.552 & \\
& RINÓN & & & 0.311 \\
& HÍGADO & & & 0.268 \\
\hline
\end{tabular}

\section{DISCusión}

La vida en las grandes alturas está influenciada por diversos factores ambientales, como: la menor presión barométrica, la hipoxia, el frío, la menor humedad, la mayor exposición a radiaciones de diverso tipo, y la carencia de algunos micronutrientes como el yodo. La menor presión parcial de oxígeno ambiental es uno de los factores que ha condicionado cambios adaptativos en el nativo de altura, a nivel antropométrico, pulmonar, hematológico, cardiovascular, metabólico, etc. $(21,26,27)$, para asegurar una oferta adecuada de oxígeno a nivel tisular.

Existen muy pocos estudios sobre el proceso oxidativo en los habitantes de las grandes alturas. El conocimiento de los niveles tisulares del malondialdehido (MDA), producto final de la peroxidación lipídica y de la actividad de la catalasa, una enzima protectora, nos permiten comprender mejor el proceso del estrés oxidativo que ocurre en estas altitudes.

En el presente estudio, ambas variables se han determinado en corazón, hígado, riñón y pulmones de dos grupos de cobayos: uno nativo de la altura $(3632 \mathrm{~m})$ y otro del nivel del $\operatorname{mar}(238 \mathrm{~m})$. Estos animales provienen de poblaciones perfectamente aclimatadas en sus respectivas altitudes.

Nuestros resultados muestran que hay un aumento significativo de los niveles de MDA en los cuatro órganos de cobayos oriundos de las grandes alturas, comparados con sus similares del nivel del mar. Según los resultados obtenidos observamos que el corazón es el órgano que presenta mayor contenido de MDA, seguido por pulmón, riñón e hígado.
En los organismos sensibles expuestos a presiones bajas de oxígeno, la disminución del metabolismo aeróbico provoca un incremento en la demanda de glucosa o glucógeno para la glicólisis anaeróbica, como un medio de compensar la pérdida de energía. Sin embargo los potenciales iónicos y eléctricos no pueden ser mantenidos a causa de la insuficiencia energética y de la alta permeabilidad de las membranas, por lo que las funcionés metabólicas y de membrana se vuelven desacopladas $(19,28)$.

Durante la hipoxia se produce la salida masiva de potasio desde el citosol y el consecuente flujo de sodio al interior de la célula, ambos fenómenos atribuibles a la insuficiencia energética y a las fallas en las bombas iónicas de membrana, activando de esta forma los canales de calcio dependientes de voltaje. Esto genera un incontrolable flujo de calcio hacia el interior de la célula, que puede generar una gran variedad de procesos citotóxicos. En relación con esto, la activación de las fosfolipasas A1, A2 y C se considera como el mecanismo más dañino en condiciones hipóxicas. Estas enzimas conducen a la hidrólisis de los fosfolípidos de membrana, con la consecuente destrucción de la membrana celular y mitocondrial, la liberación de ácidos grasos libres como el ácido araquidónico y la adicional potenciación de redistribuciones iónicas $(5,28,29)$.

El calcio puede participar, además, en el daño oxidativo mitocondrial causado por la peroxidación lipídica y la oxidación proteica. De acuerdo a esto, puede intervenir en : a) La producción incrementada de peróxido de hidrógeno por la mitocondria; b) La producción incrementada de $\mathrm{HO}^{*}$ a partir del peróxido de hidrógeno por la movilización del $\mathrm{Fe}^{+2}$ intramitocondrial, y c) Las alteraciones conformacionales de algunas proteí- 
nas de membrana, por enlazamiento del $\mathrm{Ca}^{2+}$ a la membrana interna, que pueden exponer los grupos $\mathrm{SH}$ a la oxidación por el $\mathrm{HO}^{*}(5,29)$.

La coenzima $Q$ puede proteger a la membrana interna contra la peroxidación lipídica; sin embargo, en contraste con esto, el daño oxidativo asociado con la oxidación proteica estaría potenciado por dicha coenzima $(9,19,28,29$,$) .$

En la hipoxia se incrementa la producción de glóbulos rojos y la concentración de hemoglobina circulante. Este fenómeno también estaría relacionado con el aumento de la peroxidación lipídica en la hipoxia crónica, debido a que numerosos trabajos han establecido que la hemoglobina es capaz de estimular las reacciones peroxidativas por tres diferentes vías: la primera es referida a la formación de radicales peroxil y alcoxil a partir de los hiđroperóxidos lipídicos; la segunda, a la producción de radicales hidroxil a partir del peróxido de hidrógeno por medio de las reacciones de Haber Weiss, catalizada por el hierro; y tercero, a la formación de complejos con especies reactivas del oxígeno, tales como los complejos perferril y ferril $(10,16,22)$.

Los resultados obtenidos muestran que, tanto a nivel del mar como en la altura, el corazón es el órgano que presenta mayor actividad, seguido por hígado, pulmòn y riñón. También se encontró disminución significativa de la actividad de la catalasa en los cuatro órganos de cobayos de altura comparados con los de nivel del mar, lo cual estaría relacionado con el incremento de la peroxidación lipidica encontrada en nuestro trabajo.

Diversos trabajos realizados sobre músculo liso sometido a condiciones simuladas de hipoxia crónica han demostrado que efectivamente, la actividad de la enzima catalasa disminuye notoriamente. Sin embargo, existen reportes en los cuales se pone de manifiesto que, en condiciones de hipoxia aguda hay una importante elevación de la actividad de esta enzima. Las enzimas antioxidantes deben incrementar su actividad ante la presencia de niveles elevados de radicales, tal como parece suceder durante la hipoxia aguda, pero pareceria ser que unas enzimas incrementan su actividad en mayor proporción que otras, indicando que hay unas enzimas más sensibles al cambio que otras.

Se ha notado que el incremento de las enzimas antioxidantes no se relacionan directamente entre ellas, y que la catalasa mantendria sus niveles normales o disminuidos, mientras los otros sistemas oxidantes funcionen correctamente $(12,20)$, lo que se corrobora por el hecho de que no hemos encontrado correlación entre el nivel MDA y la actividad de la enzima catalasa en los cuatro órganos de cobayos.

\section{REFERENCIAS BIBLIOGRAFICAS}

1. Berrocal N., Valdez A. 1997. Niveles plasmáticos de malondialdehido (MDA) como un indicador de la peroxidación lipídica en cobayos de altura. Tesis para optar el título de Quimico Farmacéutico, UNMSM. Lima.

2. Tiskow G. 1996. Radicales Libres en Biología y Medicina: Una Breve Revision. Gac. Cien. Vet.; 1: 44-57.

3. Bruce S, McEwen. 1998. Protective and Damaging Effects of Stress Mediators. The New England Journal of Medicine; 338: 3: 171-178.

4. Dasgupta A., Poxell D., Saldana S., Doria L. 1989. Elevated Lipid Peroxidation Products and Depletes Transferring Levels in the Plasma of Kidney Transplant Recipients. Life Sciences; 46: 67-72.

5. Horton I., White J. 1993. Lipid Peroxidation Contributes to Cardiac Deficits After Ischemia and Reperfusion of the Small Bowel. American Journal Physiology: 264: 1686-1692.

6. Ishii H, Thurman R. 1996. Oxidative Stress in Alcoholic Liver Injury. Alcoholism: Clinical and Experimental Research; 20,8:162-167.

7. Kasapoglu M., Ozben T. 2001. Alterations of Antioxidants Enzymes and Oxidative Stress Markers in Aging. Exp. Geronto: 36 (2): 209-220.

8. Kayer K., Imlay J. A. 1996. Superoxide Accelerates DNA Damage by Elevating FreeIron Levels. Proc Natl Acad Sci USA ; 93: 1363513640.

9. Marshall C., Mamary A.J., Verhoeven A.J., Marshall B.E. 1996. Pulmonary Artery NADPHOxidase is Activated in Hypoxic Pulmonary Vasoconstriction. American Journal of Respiratory Cell and Molecular Biology; 15: 633-644.

10. Marx J. L. 1987. Oxygen Free Radicals Linked to Many Diseases. Science; 235: 529-531.

11. García Bacallao, L. 2001. Plantas con propiedades antioxidantes. Rev. Cubana Invest. Biomed; 20 (3): 231-235. 
12. Lee Y., Layman D., Bell R., Norton H. 1981. Response of Glutathione Peroxidase and Catalase to Excess Dietary Iron in Rats. The Journal of Nutrition; 111: 2195-2201.

13.Soska V, Zechmeister A, Sobotová D. 1995. Blood Lipids and Lipoperoxides in Hemodialysed Patients. Scripta Medica; 68 (34): 97-102.

14. Surech MV, Menon B, Indira M. 2000. Effects of Exogenous Vitamin $C$ on Ethanol Toxicity in Rats. Indian J Physiol Pharmacol; 44(4): 40110.

15. Taylor A., Martin D., Parker J. 1983. The Effects of Oxygen Radical on Pulmonary Edema Formation. Surgery ; 94(3): 433-438.

16. Braughler J.M., Duncan L.A., Chase R.L. 1986. The Involvement of Iron in Lipid Peroxidation. Importance of Ferric to Ferrous Ratios in Initiation. J. Biol. Chem.; 261 (22): 10282-10289.

17. Esterbauer H., Schaur R., Zollner H. 1991. Chemistry and Biochemistry of 4Hydroxynonenal, Malondialdehyde and Related Aldehydes. Free Rad. Biol. \& Med. ; 11: 81-128.

18. Romero F., Bosch-Morell F., Romero M.J., Jareño E.J., Romero B., Marin N., Romá J. 1998. Lipid Peroxidation Products and Antioxidants in Human Disease. Environmental Health Perspectives; 106, 5: 1229-1233.

19.Giugliano D., Ceriello A., Paolisso G. 1996. Oxidative Stress and Diabetic Vascular Complications. Diabetic Care; 19, 3: 257-267.

20.Valenzuela A. 1991. The Biological Significance of Malondialdehyde Determination in the Assessment of Tissue Oxidative Stress. Life Sciences; 48: 301-309.
21.Ward M.P.J. and West J.B. 1995. High Altitude Medicine and Physiology, 2da Ed. By Chapman \& Hall, London. UK.

22.Xi Ming Yuan, Brunk U.T., Olsson A.G. 1995. Effects of Iron -and Hemoglobin- Loaded Human Monocyte-Derived Macrophages on Oxidation and Uptake of LDL. Arteriosclerosis, Thrombosis, and Vascular Biology; 15: 13451351.

23.Gerard-Monier D., Erdelmeier I., Régnard K., Moze-Henry N., Yadan J.C., Chaudiere J. 1998. Reaction of 1-methyl-2-phenilindole with Malondialdehyde and 4-Hydroxyalkenals. Analytical Applications to a Colorimetric Assay of Lipid Peroxidation. Chemical Research of Toxicology; 11:1176-1183.

24.Johansson L., Hakan Borg L.A. 1988. A Spectrophotometric Method for Determination of Catalase Activity in Small Tissue Samples. Analytical Biochemistry; 174: 331-336.

25.Lowry, O.H.,Rosebrough N.J.,Farr A.L. y R.J. Randall. 1951. Protein measurement with the Folin-Phenol reagent. J. Biológicas. Chem. 193: 265-275.

26. Cryer A., Bartley W. 1973. Changes in Enzyme Activities in Tissues of Rats Exposed to Hipoxia. Biochemistry Journal; 134: 1119-1122.

27.Villena J. 1998. Cambios Metabólicos en la Hipoxia Crónica. Acta Andina ; 8: 95-103.

28. Bouverot P. 1985. Adaptation to AltitudeHypoxia in Vertebrates. Cap.6: Biochemical Changes. Springer Vertag. Berlin Heidelberg. New York. Tokyo.

29. Herson P., Lee K., Pinnock R. D., Hughes J., Ashford M.L.J. 1999. Hydrogen Peroxide Induce Intracellular Calcium Overload by Activation of a Non-Selective Cation Channel in an Insulin-Secreting Cell Line. J. Biol. Chem.; 274 (2): 833-841. 